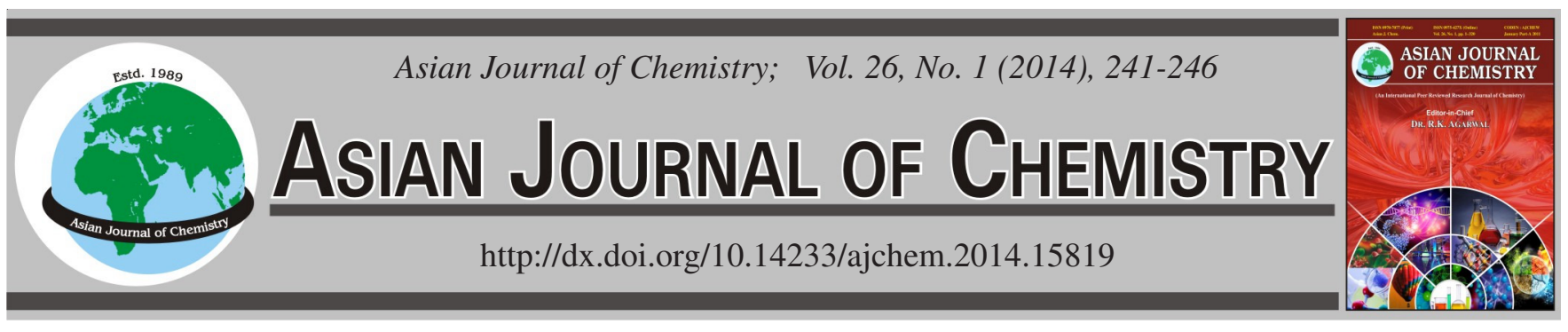

\title{
Coordination-Mediated Radical Nitration of Methyl Salicylate by Ferric Nitrate
}

\author{
Yanzhu Liu ${ }^{1,2}$, Mingming Zu ${ }^{1}$, Xiuxin Zou ${ }^{1,2}$, Qing Zheng ${ }^{1,2}$, XIA Li $^{1,2}$, XueZhen Zhou ${ }^{2}$, \\ Qun TANG ${ }^{1,3}$, Shihan Zhang ${ }^{1,3}$, Ling Zhang ${ }^{1,2}$ and YongXiu $\mathrm{LI}^{1,2,3, *}$
}

\begin{abstract}
${ }^{1}$ Research Center for Rare Earths \& Micro/Nano Functional Materials, Nanchang University, Nanchang 330031, P.R. China ${ }^{2}$ Department of Chemistry, Nanchang University, Nanchang 330031, P.R. China

${ }^{3}$ Institute of Advanced Study, Nanchang University, Nanchang 330031, P.R. China
\end{abstract}

*Corresponding author: Fax: +86 791 83969240; Tel: +86 791 88305741; E-mail: yxli@ncu.edu.cn

\begin{abstract}
Nitration of methyl salicylate was performed by ferric nitrate in refluxing ethyl acetate solution. A coordination-mediated radical nitration process was proposed based on the results of electronic absorption spectra, cyclic voltammetry and electrospray ionization mass spectra. It was the coordination of methyl salicylate with ferric nitrate that promoted the splitting of $\mathrm{N}-\mathrm{O}$ bonds of nitrate group in ferric nitrate and resulted in the formation of nitro radicals, oxygen radicals and complex radicals. The nitro radicals reacted with methyl salicylate or its complexes with iron to give a series of nitration products and Fe(II) ions. Meanwhile, oxygen radicals hydrolyzed to hydroxide which precipitated free ferric ions to isolate solid ferric oxides.
\end{abstract}

Keywords: Methyl salicylate, Ferric nitrate, Coordination, Radicals, Nitration.

\section{INTRODUCTION}

The industrially nitration requires the use of corrosive liquid phase nitric acid and sulfuric acid mixture ${ }^{1-9}$. Over the past two decades, remarkable progress has been made in the nitration reactions using metal nitrates as nitration agents or co-catalysts for improving the nitration efficiency and reducing the damage to the equipment and environment ${ }^{1,10-23}$. Particular attention has also been directed to the nitration reactions of drug or bio-molecules due to their significant roles in numerous physiological processes ranged from regulation of cardiovascular function to memory formation ${ }^{24-30}$.

We have studied the facile nitration reaction of methyl salicylate with transition metal nitrates to afford the corresponding nitro compounds ${ }^{31-34}$. In the cases of $\mathrm{Fe}$ (III) and $\mathrm{Cu}$ (II) nitrates as nitration reagents, we observed the isolation of metal oxides and hydroxides, which has allowed us to recover metal materials by a simple filtration process. The regioselectivity of nitration is significantly higher than that of general nitration using nitric acid and sulfuric acid mixture as nitrating reagents. For example, in the case of nitration of methyl salicylate with ferric nitrate, the regioselectivity $(\mathrm{P} / \mathrm{O})$ presented by the ratio of methyl 5-nitrosalicylate $(\mathrm{P})$ to methyl 3-nitrosalicylate $(\mathrm{O})$ is up to 5.3. However, the molecular mechanism of this nitration is still unclear. Moreover, the detail mechanism of nitration occurred in neutral solution containing metal nitrates is obscure.
Therefore, seeking new standpoints for the explanation of nitration reaction process remains an important challenge for chemists $^{35}$.

Nitration is usually considered as an electrophilic aromatic substitution reaction ${ }^{35}$. With this idea, metal ions in a nitration reaction have been suggested to play a catalytic role to lead a higher concentration of $\mathrm{NO}_{2}{ }^{+}$by an accentuation of the Bronsted acidity of nitric acid ${ }^{1,11-12}$. However, the nitration process using metal nitrates as nitrating reagents might not available through nitronium ion in neutral or basic solution because the formation of nitronium ion favors condition of high acidity. Thus, radical mechanism was proposed ${ }^{1,36}$. For example, Cornelis and Laszlo ${ }^{1}$ proposed a plausible mechanism to explain the nitration of phenol by ferric nitrate based on the suggestion on the formation of nitro radical and $\mathrm{Fe}^{2+}$, however, no direct evidence was provided and the explanation is poor.

In this paper, we suggest a coordination-mediated radical nitration of phenol by ferric nitrate because that ferric ions show a typical coordination reaction toward phenol compounds. Therefore, by analyzing the electronic absorption spectra, cyclic voltammetry and electrospray ionization mass spectra of mixture solution of methyl salicylate and ferric nitrate, we paid attention to demonstrate or identify the intermediates formed during the nitration process of methyl salicylate with ferric nitrate, including radicals and coordination compounds. 
It can be concluded that the nitration was indeed mediated by the coordination between ferric nitrate and methyl salicylate. And a novel coordination mediated radical nitration mechanism was proposed to illustrate all the experimental results. This mechanism provides promise not only for designing novel nitration routes of valuable compounds, but also for understanding physiological efficacy of methyl salicylate, nitrate group and iron ions in biological systems since they share the common components either in food or in pharmaceuticals ${ }^{37}$.

\section{EXPERIMENTAL}

The ESIMS were determined on a Finnigan LCD mass spectrometer; the concentration of the samples were about $1 \mu$ $\mathrm{mol} \mathrm{dm} \mathrm{d}^{-1}$. The diluted solutions were electrosprayed at a flow rate of $5 \times 10^{-6} \mathrm{dm}^{-3} \mathrm{~min}^{-1}$ with a needle voltage of $+4.5 \mathrm{kv}$. The mobile phase was methanol and the samples run in the positive-ion mode. Cyclic voltammetry were performed in a three-electrode system of a CHI660 electrochemical workstation. Ethyl acetate and $\mathrm{KNO}_{3}$ used as solvent and supporting electrolyte, $\mathrm{Pt}-\mathrm{C}$ as working electrode, $\mathrm{Ag} / \mathrm{AgCl}$ as reference electrode,Pt as auxiliary electrode.

Nitration reaction of methyl salicylate and ferric nitrate: $\mathrm{Fe}\left(\mathrm{NO}_{3}\right)_{3} \cdot 9 \mathrm{H}_{2} \mathrm{O}$ (A.R.) was dissolved in ethyl acetate solution (A.R. $20 \mathrm{~mL}$ ) in a $100 \mathrm{~mL}$ flask, then methyl salicylate was added. The mixture solution was heated to reflux under stirring with a magnetic stirrer. For a certain interval reaction period, $0.2 \mathrm{~mL}$ reaction solution was taken out and diluted to $10 \mathrm{~mL}$ with ethyl acetate for the electronic absorption spectra characterization carried out by a Shimadzu UV3100 spectrophotometer. Oxygen radicals were confirmed by hydroxylamine oxidation in the reaction solution as ferric nitrate reacted with methyl salicylate for $40 \mathrm{~min}$ at $90^{\circ} \mathrm{C}$. To this yellow reaction solution, hydroxylamine hydrochloride, 4-hydroxy benzenesulfonic acid and 1-naphthylamine were added.

\section{RESULTS AND DISCUSSION}

The addition of methyl salicylate into ethyl acetate solution containing ferric nitrate led to a typical red-violet complex. Fig. 1 shows the electronic absorption spectra of mixture solution of methyl salicylate and ferric nitrate as well as their reaction solutions after refluxing different times. In the electronic absorption spectra of mixture solution of ferric nitrate and methyl salicylate shown in Fig. 1a, the broad absorption band within $430 \mathrm{~nm}$ and $750 \mathrm{~nm}$ with maximum at $550 \mathrm{~nm}$ can be identified to the charge transfer band from the HOMO of the phenol to the $\mathrm{d}_{\pi}$-orbital of the iron atom, indicating that methyl salicylate were coordinated to $\mathrm{Fe}$ (III) ions. This broad absorption band was enhanced upon refluxing 20 min (Fig.1b) and was weakened with refluxing time prolongation to $40 \mathrm{~min}$ (Fig. 1c), indicating that the formed coordination compounds are intermediates because their concentration was increased at first with the increase of reaction temperature and decreased at last with the formation of nitration products. Finally, the red-violet solution became yellow and the intensity of absorption peak at $550 \mathrm{~nm}$ decreased to near zero. These facts demonstrated that the nitration of methyl salicylate by ferric nitrate is mediated by the coordination between methyl salicylate and ferric nitrate.

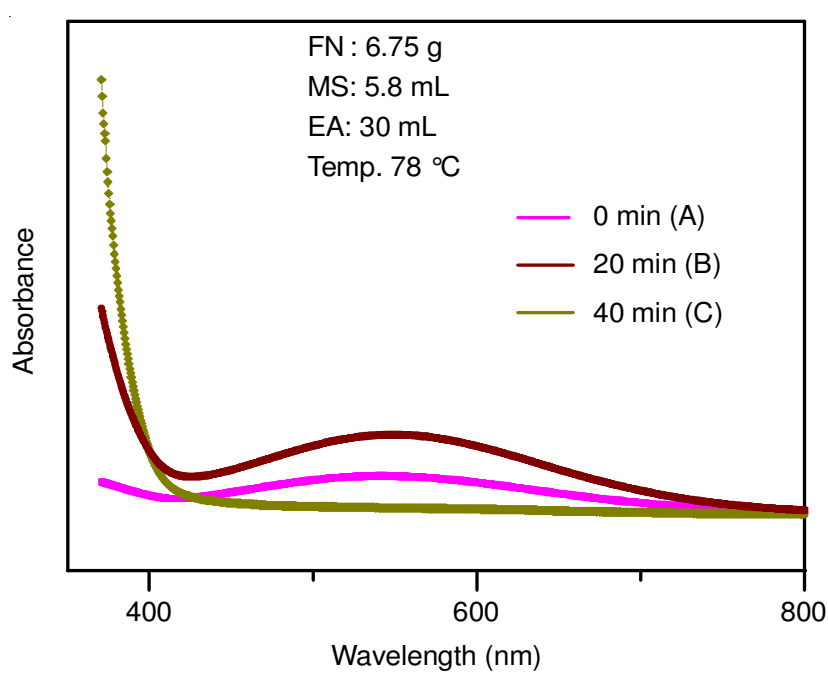

Fig. 1 Electronic absorption spectra of mixture solution of methyl salicylate and ferric nitrate in ethyl acetate; (a) at room temperature (0 min); (b) refluxing for $20 \mathrm{~min}$; (c) refluxing for $40 \mathrm{~min}$

Cyclic voltammetry of the reaction solution of iron(III) nitrate and methyl salicylate: To identify the role of coordination between methyl salicylate with ferric nitrate, cyclic voltammetry method was applied. Fig. 2 shows the cyclic voltammetry curves of different solutions. There are two oxi dation-reduction peaks of pure ferric nitrate (Fig. 2a) in the
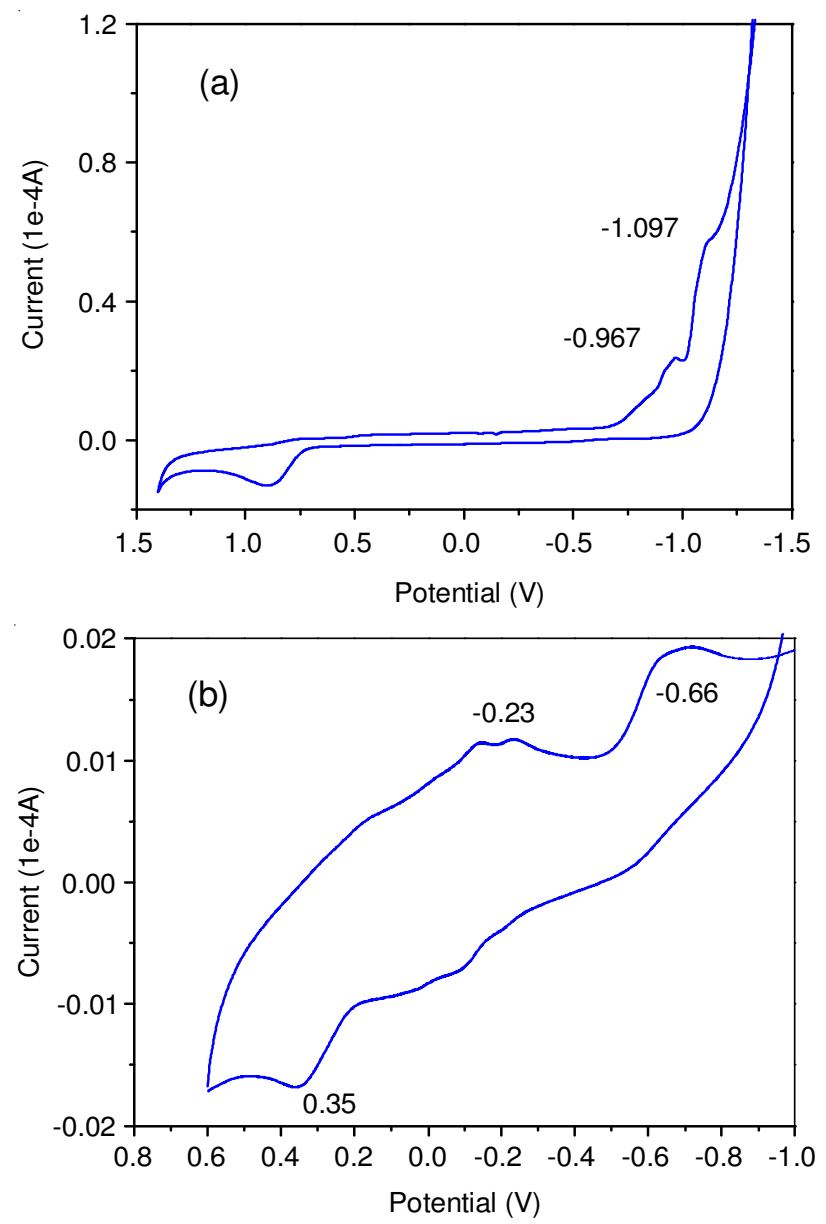

Fig. 2 Cyclic voltammetry of different solutions (scan rate: $0.01 \mathrm{~V} / \mathrm{s}$ ) (a) The solutin of ferric nitrate (dissolved in $0.1 \mathrm{~mol} / \mathrm{L} \mathrm{KNO}_{3}$ ); (b) The reaction solution of methyl salicylate and ferric nitrate(dissolved in $0.1 \mathrm{~mol} / \mathrm{L} \mathrm{KNO}_{3}$ ) 
cyclic voltammetry curve of ferric nitrate solution due to the oxidation-reduction of ferric-ferrous ions. These two oxidationreduction peaks also emerged in the cyclic voltammetry curve of mixture solution of methyl salicylate and ferric nitrate (Fig. 2b). However, the reduction potential is more positive than those of ferric nitrate. This fact indicated that the formation of coordination complexes between methyl salicylate and ferric nitrate can make the reduction reaction of ferric ion more easily which can be further demonstrated by the formation of $\mathrm{Fe}^{2+}$. Addition of 1,10-phenanthroline into the resulting yellow solution caused the yellow color changed to red immediately. The wide band ranging from 400 to $550 \mathrm{~nm}$ in the electronic absorption spectra (Fig. 3) indicated the existing of ferrous ions which was reduced from ferric ions coordinated by methyl salicylate.

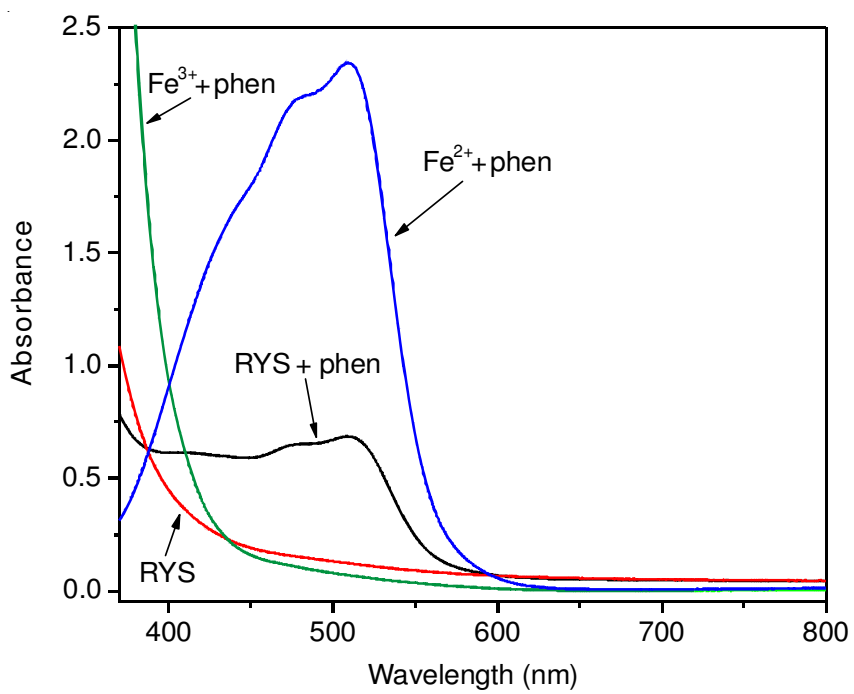

Fig. 3 Electronic absorption spectra of yellow reaction solutions (YRS) with and without addition of 1,10- phenanthroline; showing the existing of $\mathrm{Fe}(\mathrm{II})$ in yellow reaction solution

Evidence for the formation of complexes between iron(III) nitrate and methyl salicylate by ESIMS study: The main species or intermediates formed in the mixing solution of ferric nitrate with methyl salicylate before and after refluxing can be evaluated from their ESIMS shown in Fig. 4. There are four groups of peaks in the ESIMS of the mixture solution of ferric nitrate and methyl salicylate at room temperature (Fig. 4a). The first group refers to iron nitrates, including $\left[\mathrm{Fe}\left(\mathrm{NO}_{3}\right)_{2}\left(\mathrm{H}_{2} \mathrm{O}\right)_{2}\right]^{+}(\mathrm{m} / \mathrm{z}=217),\left[\mathrm{Fe}\left(\mathrm{NO}_{3}\right)_{3} \mathrm{H}_{3} \mathrm{O}\right]^{+}(\mathrm{m} / \mathrm{z}=261)$ and $\left[\mathrm{Fe}\left(\mathrm{NO}_{3}\right)_{3}\left(\mathrm{HNO}_{3}\right)\right]^{+}(\mathrm{m} / \mathrm{z}=305)$. The second group includes the complexes of ferric nitrate with methyl salicylate anion (denoted as MS-H), such as $\left[\mathrm{Fe}(\mathrm{MS}-\mathrm{H})\left(\mathrm{NO}_{3}\right)\right]^{+}(\mathrm{m} / \mathrm{z}=269)$, $\left[\mathrm{Fe}(\mathrm{MS}-\mathrm{H})_{2}\right]^{+}(\mathrm{m} / \mathrm{z}=358)$ and $\left[\mathrm{Fe}(\mathrm{MS}-\mathrm{H})_{2} \mathrm{CH}_{3} \mathrm{OH}\right]^{+}(\mathrm{m} / \mathrm{z}=$ $390)$. The third group is the complexes of ferric nitrate and neutral methyl salicylate with molar ratios of 1:1, 1:2, 1:3, including $\left[\mathrm{Fe}(\mathrm{MS})\left(\mathrm{NO}_{3}\right)_{2}\right]^{+}(\mathrm{m} / \mathrm{z}=332),\left[\mathrm{Fe}\left(\mathrm{NO}_{3}\right)_{2}(\mathrm{MS})_{2} \mathrm{CH}_{3}\right.$ $\left.\mathrm{OH}\left(\mathrm{H}_{2} \mathrm{O}\right)\right]^{+}(m / z=532-534),\left[\mathrm{Fe}\left(\mathrm{NO}_{3}\right)_{2}(\mathrm{MS})_{3} \mathrm{CH}_{3} \mathrm{OH}\left(\mathrm{H}_{2} \mathrm{O}\right)\right]^{+}$ $\mathrm{m} / \mathrm{z}=683.7-686)$. The last group relates to the dimer of ferric nitrate and its complexes with methyl salicylate or MS-H, such as $\left[\mathrm{Fe}_{2}\left(\mathrm{NO}_{3}\right)_{5}\right]^{+}(\mathrm{m} / \mathrm{z}=422),\left[\mathrm{Fe}_{2}\left(\mathrm{NO}_{3}\right)_{5}(\mathrm{MS})\left(\mathrm{H}_{2} \mathrm{O}\right)_{2}\right]^{+}(\mathrm{m} / \mathrm{z}=$ 610.9), $\left[\mathrm{Fe}_{2}(\mathrm{MS}-\mathrm{H})_{2}\left(\mathrm{NO}_{3}\right)_{5}\left(\mathrm{CH}_{3} \mathrm{OH}\right)_{2}\left(\mathrm{H}_{2} \mathrm{O}\right)\right]^{+}$(804). These facts demonstrated that methyl salicylate can coordinate to ferric nitrate as neutral or anion ligand to form a series of complexes with molar ratio of $3: 1,2: 1,1: 1$.

Compared to Fig. 4a, some new peaks, such as $m / z=315.8$, 332, 348, 362, 377.7, 470.9, 486.4, 609.9, 666.9 can be observed from the ESIMS of solution after refluxing $20 \mathrm{~min}$ (Fig. 4b). At the same time, the relative intensity of peaks identified to iron nitrates and their complexes with methyl salicylate has been changed. For example, the relative intensity of peaks corresponding to the complexes of ferric nitrate and methyl salicylate with molar ratio of 1:1 was increased with the decrease of relative intensity of peak to ferric nitrate. Meanwhile, the peaks corresponding to the complexes of ferric nitrate and methyl salicylate with molar ratio of 1:2 were vanished. These facts indicated that refluxing at high temperature is beneficial to the formation of complex with molar ratio of ferric nitrate to methyl salicylate 1:1 rather than 1:2. Furthermore, with refluxing time prolongation from 20 to $40 \mathrm{~min}$ (Fig. 4c), the relative intensity of peaks corresponding to the
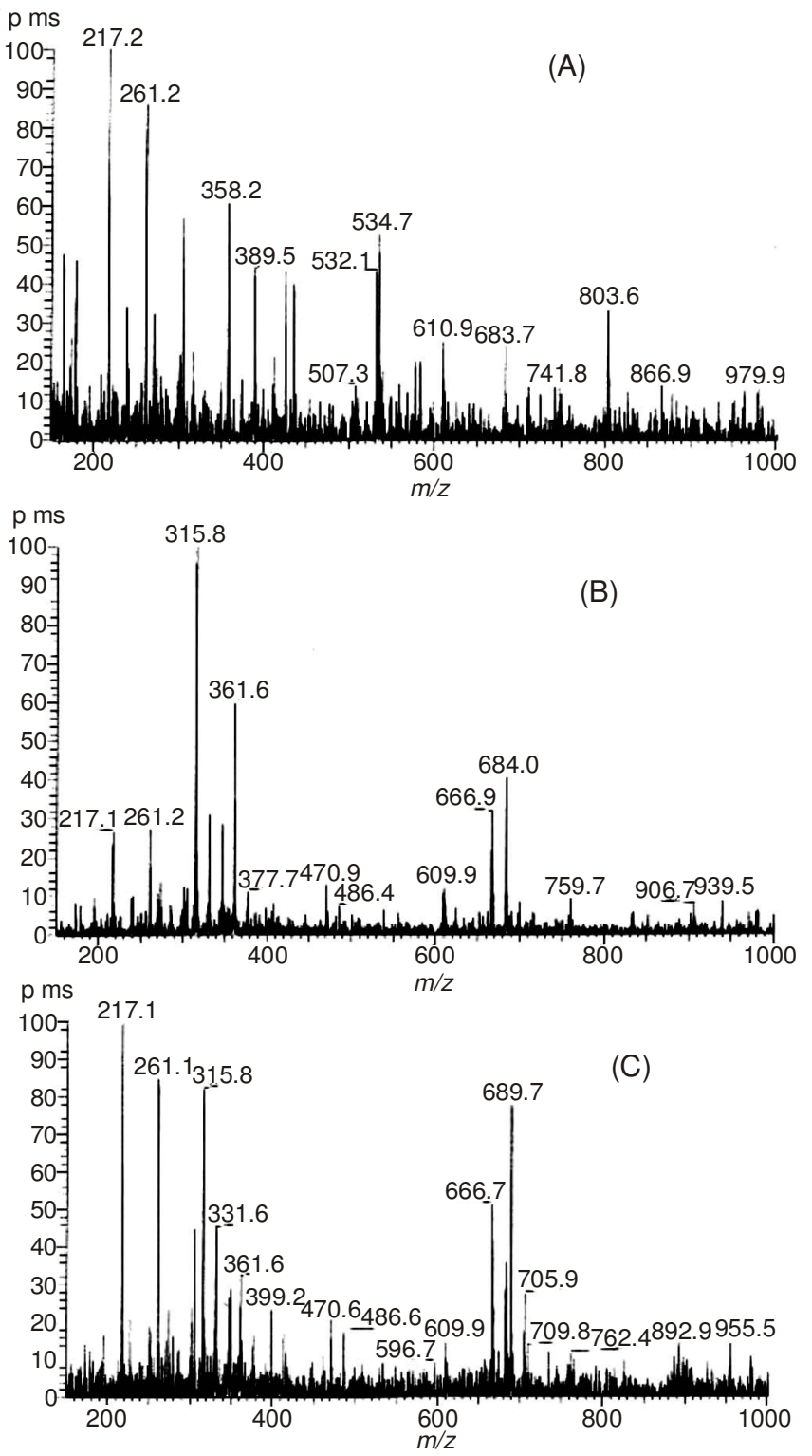

Fig. 4 ESIMS of mixture solution of methyl salicylate and ferric nitrate in ethyl acetate; (a) at room temperature; (b) refluxing for $20 \mathrm{~min}$; (c) refluxing for $40 \mathrm{~min}$ 
1:1 complexes of ferric nitrate and methyl salicylate was also decreased, indicating this complex formed previously has been transferred to final nitration products.

In order to illustrate the nitration process via coordination intermediates, we suggested that the key step of nitration reaction was involved the splitting of $\mathrm{O}-\mathrm{N}$ bonds in complexes such as $\mathrm{Fe}(\mathrm{MS})\left(\mathrm{NO}_{3}\right)_{3}$ and the liberating of radicals such as oxygen and nitro radicals. With this suggestion, most of the new peaks appeared in the ESIMS of solution after refluxing 20 and 40 min can be assigned to the intermediates derived from the 1:1 complexes of ferric nitrate and methyl salicylate as following reactions:

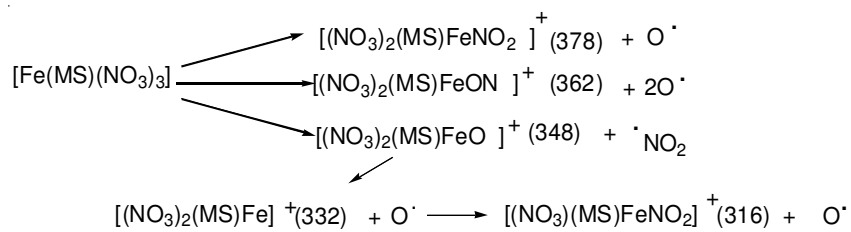

With similar consideration, some other new peaks in Fig. $4 \mathrm{~b}$ and $\mathrm{c}$ can be identified to the intermediates derived from the 1:2 and 1:3 complexes of ferric nitrate and methyl salicylate by following reactions:

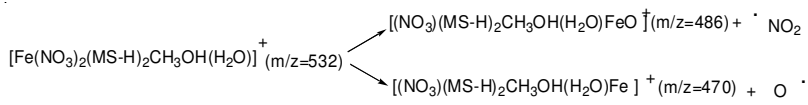

$\left[\mathrm{Fe}\left(\mathrm{NO}_{3}\right)_{2}(\mathrm{MS}-\mathrm{H})_{3} \mathrm{CH}_{3} \mathrm{OH}\left(\mathrm{H}_{2} \mathrm{O}\right)\right]^{+}(\mathrm{m} / \mathrm{z}=683.7) \longrightarrow\left[\left(\mathrm{NO}_{3}\right)(\mathrm{MS}-\mathrm{H})_{3} \mathrm{CH}_{3} \mathrm{OH}\left(\mathrm{H}_{2} \mathrm{O}\right) \mathrm{FeNO}_{2}\right]^{+}(\mathrm{m} / \mathrm{z}=667)+\mathrm{O} \cdot$

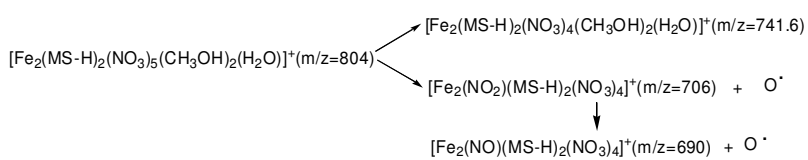

Identification of the oxygen radicals: The oxygen radicals formed in above reactions have been confirmed by a hydroxylamine oxidation method ${ }^{38}$. As shown in Fig. 5, the electronic absorption spectra of yellow reaction solution (YRS) with 4-hydroxy benzenesulfonic acid, hydroxylamine hydrochloride and 1-naphthylamine shows two typical absorption bands at $405 \mathrm{~nm}$ and $520 \mathrm{~nm}$ (Fig. 5c). The band at $402 \mathrm{~nm}$ is attributed to the product formed by the reaction of 4-hydroxy benzenesulfonic acid and 1-naphthylamine (Fig. 5b). The band at $520 \mathrm{~nm}$ is owing to the red complex formed by the reaction of 4-hydroxyl benzenesulfonic acid and 1-naphthylamine with the oxidation product nitrite of hydroxylamine hydrochloride by oxygen radicals, demonstrating the existing of oxygen radicals in the reaction solution of ferric nitrate and methyl salicylate. The release of oxygen radicals can also be demonstrated by the isolation of yellow precipitate hydrate ferric oxide $^{31}$ during the nitration process of methyl salicylate with ferric nitrate. It is known that the oxygen radicals can be hydrolyzed to hydroxide which precipitated the unreduced ferric ions to form hydrated ferric oxides.

Nitration mechanism via radicals: Based on the facts above, the nitration reaction of methyl salicylate with ferric nitrate can be considered to occur via a coordination-mediated

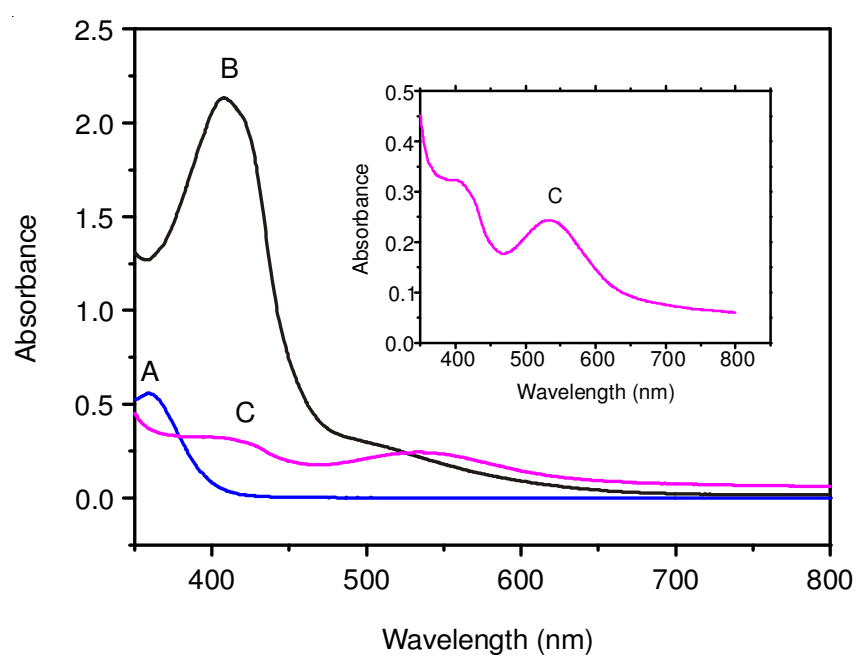

Fig. 5. Identification of oxygen radicals in yellow reaction solution (YRS) of ferric nitrate reacting with methyl salicylate at $90{ }^{\circ} \mathrm{C}$ for $40 \mathrm{~min}$ by hydroxylamine oxidation method; (a) YRS + 0.1 g hydroxylamine hydrochloride. (b) YRS + 0.1 g 4-hydroxyl benzenesulfonic acid and $0.05 \mathrm{~g}$ 1-naphthylamine; (c) YRS + $0.1 \mathrm{~g}$ 4-hydroxyl benzenesulfonic acid, $0.05 \mathrm{~g} 1$-naphthylamine and $0.1 \mathrm{~g}$ hydroxylamine hydrochloride (diluted to $30 \mathrm{~mL}$ )

radical mechanism. As shown in Scheme-I, the mechanism includes three main steps: coordination, N-O bond splitting with radical formation, nitration followed by complex disassociation as well as hydrate ferric oxide isolation and $\mathrm{Fe}$ (II) release. It was the coordination between ferric nitrate and methyl salicylate that resulted in the formation of a series of complexes with different molar ratios of ferric nitrate and methyl salicylate, which was demonstrated by electronic absorption spectra and ESIMS. The splitting of O-N bonds in ferric nitrate was facilitated by the coordination with methyl salicylate and led to the liberation of nitro and oxygen radicals which have been identified by chemical method or explained using results of ESIMS, nitration and the isolation of hydrated ferric oxide. The pararegioselectivity data reported previously demonstrated that the nitration was mainly occurred between nitro radicals and methyl salicylate as well as the complexes of methyl salicylate with ferric nitrate, because nitro radicals favors attaching to the para position of phenolic hydroxide group when methyl salicylate was coordinated with ferric nitrate because of the steric hendance effect. If the nitration had occurred as an inner sphere mechanism, e.g. the splitting of $\mathrm{N}-\mathrm{O}$ bonds in complexes had occurred synchronous with the nitration, the nitro group should favor attaching to the ortho position of hydroxide group in phenolic ring. Once the coordinated methyl salicylate was nitrated, it would disassociate to iron ions and nitrated methyl salicylates due to their weak coordination. Then, the iron ions were hydrolyzed to hydrated iron oxide with few of nitrate groups and complexes.

\section{Conclusion}

In summary, a likely coordination-mediated radical nitration mechanism has been proposed for explaining the nitration using metal nitrates as nitrating reagents. The results of electronic absorption spectra, cyclic voltammetry and ESIMS of mixture solutions of ferric nitrate and methyl salicylate with different reaction temperature and times have 

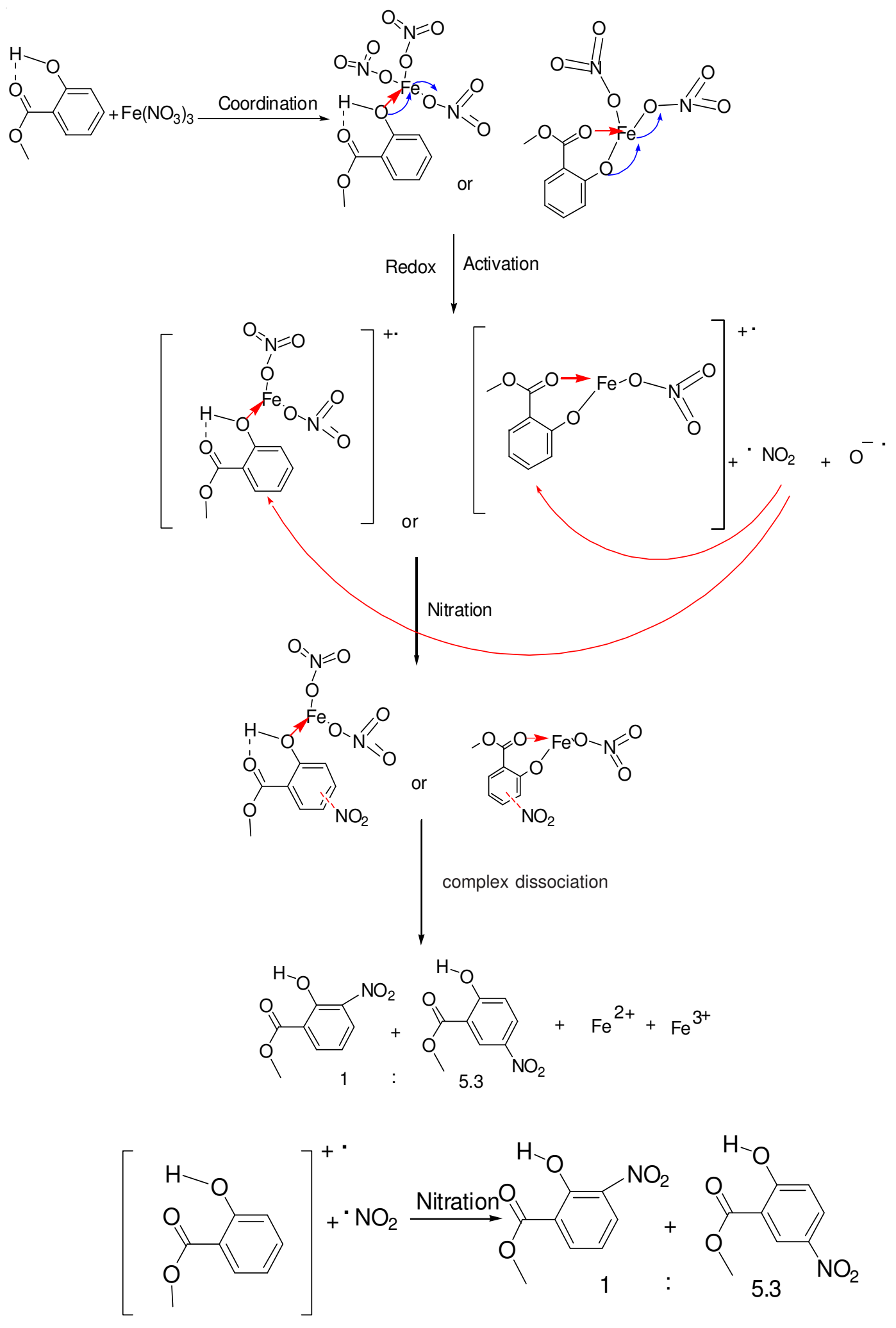

$$
\begin{gathered}
\mathrm{O} \cdot+\mathrm{H}_{2} \mathrm{O} \longrightarrow \mathrm{OH}+-\mathrm{OH} \\
\mathrm{Fe}\left(\mathrm{NO}_{3}\right)_{3}+-\mathrm{OH} \longrightarrow\left[\mathrm{Fe}(\mathrm{OH})_{2}\left(\mathrm{NO}_{3}\right)\right]^{\downarrow}+\mathrm{HNO}_{3} \\
{\left[\mathrm{Fe}(\mathrm{OH})_{2}\left(\mathrm{NO}_{3}\right)\right]+\mathrm{H}_{2} \mathrm{O} \longrightarrow \mathrm{Fe}(\mathrm{OH})_{3} \downarrow+\mathrm{HNO}_{3}} \\
2 \mathrm{Fe}(\mathrm{OH})_{3} \longrightarrow \mathrm{Fe}_{2} \mathrm{O}_{3} 3 \mathrm{H}_{2} \mathrm{O} \downarrow
\end{gathered}
$$

Scheme-I: Coordination-mediated radical nitration process 
demonstrated the formation of complexes and radicals. It is the coordination between methyl salicylate and Fe(III) ion that initiates the formation of $\mathrm{NO}_{2}$ and $\mathrm{O}$ radicals as well as coordinated methyl salicylate radical cation $\mathrm{NO}_{2}$ radicals react with methyl salicylate or coordinated methyl salicylate radical cation through radical nitration substitution to form final nitrated products.

\section{ACKNOWLEDGEMENTS}

This work is Financially Supported by the Natural Science Foundation of China (21161014), National key basic Research Development Program (973 Program) project of China (2012CBA01204), the Foundation of Training Academic and Technical Leaders for Main Majors of Jiangxi (2007DD00800).

\section{REFERENCES}

1. A. Cornelis and P. Laszlo, Synthesis, 909 (1985).

2. J.L. Grenier, J.P. Cotelle, P. Catteau, Synth. Commun., 29, 1201(1999).

3. J.M. Mellor, S. Mittoo, R. Parkes and R.W. Millar, Tetrahedron, 56, 8019 (2000).

4. N. Haghnazari, C. Karami, K. Ghodrati and F. Maleki, Int. Nano Lett., 1, 30 (2011).

5. J.M. Riego, Z. Sedin, J. Zaldívar, N.C. Marziano and C. Tortato, Tetrahedron Lett., 37, 513 (1996).

6. F. Chávez, S. Suárez and M.A. Díaz, Synth. Commun., 24, 2325 (1994).

7. N. Iranpoor, H. Firouzabadi, N. Nowrouzi and D. Firouzabadi, Tetrahedron Lett., 47, 6879 (2006).

8. A. Bose, W.P. Sanjoto, S. Villarreal, H. Aguilar and B.K. Banik, Tetrahedron Lett., 48, 3945 (2007).

9. P.-C. Wang, M. Lu, J. Zhu, Y.-M. Song and X.- Xiong, Catal. Commun., 14, 42 (2011).

10. P.J. Campos, B. García and M.A. Rodríguez, Tetrahedron Lett., 41, 979 (2000)

11. H. Firouzabadi, N. Iranpoor and M. Zolfigol, Synth. Commun., 27, 3301 (1997).

12. H. Suzuki, S. Yonezawa, N. Nonoyama and T. Mori, J. Chem. Soc., Perkin Trans. I, 2385 (1996).
13. R.R. Bak and A.J. Smallridge, Tetrahedron Lett., 42, 6767 (2001).

14. R. Rajagopal and K.V. Srinivasan, Synth. Commun., 33, 961 (2003).

15. N. Iranpoor, H. Firouzabadi, M. AliZolfigol, Synth. Commun., 28, 2773 (1998).

16. A.K. Bose, S.N. Ganguly, M.S. Manhas, S. Rao, J. Speck, U. Pekelny and E. Pombo-Villars, Tetrahedron Lett., 47, 1885 (2006).

17. M.A. Zolfigol, E. Ghaemi, E. Madrakian, Synth. Commun., 30, 1689 (2000).

18. S. Dinçtürk and J.H. Ridd, J. Chem. Soc. Perkin Trans. II, 961 (1982).

19. S. Dinçtürk and J.H. Ridd , J. Chem. Soc. Perkin Trans. II, 965 (1982).

20. H.B. Sun, R. Hua and Y. Yin, J. Org. Chem., 70, 9071 (2005).

21. A.R. Pourali and F. Fatemi, Chin. Chem. Lett., 21, 1283 (2010).

22. N. Nowrouzi and M. Zareh Jonaghani, Tetrahedron Lett., 52, 5081 (2011).

23. X.M. Ma, B.D. Li, M. Lu and C.X. Lv, Chin. Chem. Lett., 23, 73 (2012).

24. M. De Lucia, L. Panzella, O. Crescenzi, A. Napolitano, V. Barone and M. d'Ischia, Bioorg. Med. Chem. Lett., 16, 2238 (2006).

25. C. Fimognari and P. Hrelia, Mutat. Res. Rev. Mutat., 635, 90 (2007).

26. A. Lapczynski, L. Jones, D. McGinty, S. Bhatia, C. Letizia and A. Api, Food Chem. Toxicol., 45, S428 (2007).

27. L. Peri, D. Pietraforte, G. Scorza, A. Napolitano, V. Fogliano and M. Minetti, Free Radic. Biol. Med., 39, 668 (2005).

28. M. d'Ischia, L. Panzella, P. Manini and A. Napolitano, Curr. Med. Chem., 13, 3133 (2006).

29. J.L. Williams, P. Ji, N. Ouyang, L. Kopelovich and B. Rigas, Exp. Cell Res., 317, 1359 (2011).

30. Y. Zhang, Y. Huang, X. Deng, Y. Xu, Z. Gao and H. Li, Eur. J. Pharmacol., 680, 95 (2012).

31. Y.Z. Liu, X. Li, L. Zhang and Y.X. Li, Appl. Chem. Ind., 38, 1571 (2009).

32. Y.Z. Liu, L. Zhang, X. Li and Y.X. Li, Acta Phys. Chim. Sin., 25, 2118 (2009).

33. Y.Z. Liu, Y.X. Li, X. Li and L. Zhang, Appl. Chem., 27, 432 (2010).

34. Y.Z. Liu, Y.X. Li, L. Zhang and X. Li, Acta Cryst., E65, o1716 (2009).

35. J.F. Queiroz, J.W.M. Carneiro, A.A. Sabino, R. Sparrapan, M.N. Eberlin and P.M. Esteves, J. Org. Chem., 71, 6192 (2006).

36. G. Elias, B.J. Mincher, S.P. Mezyk, J. Muller and L.R. Martin, Radiat. Phys. Chem., 80, 554 (2011).

37. S. Ito, Y. Ishikawa, S. Nishino, T. Kobayashi, S. Ohba and Y. Nishida, Polyhedron, 17, 4379 (1998).

38. G.C. Zhen, S.Y. Xiao, X.J. Mu and Z.N. Xia, Guangzhou Chem., 31, 37 (2006). 